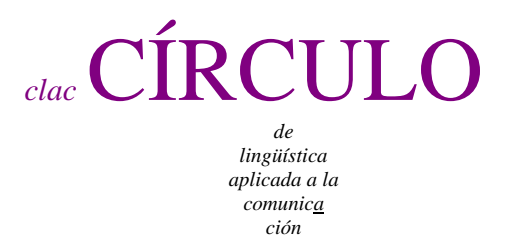

$69 / 2017$

\title{
DISCOURSE-PRAGMATIC VARIATION AND CHANGE 4
}

http://dipvac.org

Helsinki, 28-30 May2018

Discourse-Pragmatic Variation \& Change (DiPVaC) is a biennial international conference series which was devised to further the quantitative analysis of variation and change at the level of discourse-pragmatics. DiPVaC4 will be held from May 28 to 30, 2018, at the University of Helsinki.

The confirmed plenarists are:

Yael Maschler, University of Haifa

Terttu Nevalainen, University of Helsinki

Heike Pichler, Newcastle University

The first call for papers will go out in the spring of 2017.

Published: February 28, 2017

Helsinki 2018: Discourse-Pragmatic Variation and Change 4 Círculo de Lingüística Aplicada a la Comunicación 69, 349.

http://www.ucm.es/info/circulo/no69/discourse.pdf

http://revistas.ucm.es/index.php/CLAC

http://dx.doi.org/10.5209/CLAC.55326 